\title{
Prismatic shell repairs by hemoctyes in the extrapallial fluid of the Pacific Oyster, Crassostrea gigas
}

\author{
Sang-Man $\mathrm{Cho}^{1}$ and Woo-Geon Jeong ${ }^{2}$ \\ ${ }^{1}$ Department of Aquaculture and Aquatic Sciences, Kunsan National University, 1170 Miryong, Kusan, Jeonbuk 573-160, \\ Korea \\ ${ }^{2}$ Department of Marine biology and Aquaculture \& Institute of Marine Industrial Science, Gyeongsang National University, \\ 445 Inpyeong, Tongyoeng, Gyeongnam 650-160, Korea
}

\begin{abstract}
To understand the role of hemocytes in the shell repair process, a hole was drilled in the right valves of the Pacific oyster, Crassostrea gigas, and the repair process was observed. Histological observations suggested that the exterior surface of the shell was repaired by aggregated hemocytes. The nuclei of the hemocytes were cleary stained in the regenerated shell while appearing fragmented after calcification at the $7^{\text {th }}$ day. Globular calcium granules were genegenerated from the hemocytic monolyer after 6 days of incubation which were morphologically and chemically identical with those from prismatic shell. Our finding suggested that the repaired prismatic shell was composed by aggregated hemocytes and that their endogenous calcium component might support the nucleation of calcium biomineralization during shell repair.
\end{abstract}

Key words: Pacific oyster; Crassostrea gigas Shell repair; Hemocyte, Biomineralization

\section{INTRODUCTION}

Molluscan shell provides marine bivalve with shelter from predators and unfavorable environmental conditions. They also provide growth potential for the bivalve because its body size is restricted by the shell volume. Because of the biological and ecological importance of the molluscan shell to the animal, its structure and formation have been intensively studied over decades, but many aspects of the biomineralization process remain unclear (Simkiss and Wilbur, 1989).

Molluscan shell is composite by orgnic matrix. The matrix is presumed to mediate a shell formation because of its close association with the mineral phase and influence on crytal growth (Johnstone et al., 2008). The microstructure of the shell layers is controlled by proteins secreted by the epithelial cells

Received September 7, 2011 ; Accepted September 26, 2011

Corresponding author: Woo-Geon Jeong

Tel: +82 (55) 772-9151 e-mail: jwg@gnu.ac.kr

$1225-3480 / 24399$ of different regeions in the mantle (Zhang and Zhang, 2006; Marin et al., 2008).

The EPF is considered to play a fundamental role in shell calcification. The molluscan extrapallial fluid (EPF) is enclosed between the inner surface of the shell and the mantle which is supersaturated by $\mathrm{CaCO}_{3}$ solution containing several organic molecules involed in shell formation (Kadar et al., 2009). The EPFs associated with the marginal and central zones of mantle may have different chemical composition. The central zone EPF contains a complex mixture of inorganic ions and organic components including amino acids, proteins, acid mucopolysaccharides, carbohydrates, and probably lipids (Wilbur and Bernhardt, 1984).

The calcium carbonate crystals are formed on the inner shell surface in association with the EPF and organic matrix, both drived from secretion of mantle epthelium (Wilbur and Bernhardt, 1984). Although the growth of molluscan shell crytals is usually thought to be initated from extracellular orgnic matrix in extrapallial fluid, hemocyte, being abundant 
in EPF, also involve in the process as a calcium conveyor from mantle to shell surface (Kadar et al., 2009 Cho et al., 2011).

Although Mount et al. (2004) reported that hemocytes might function as the nuclei for calcium crystallization at the mineralization front of regenerated shell, the function of hemocytes in shell repair remains still obscure. Here we founded an evidence of direct involvement of hemocyte on peristracum formation. The aim of this study, therefore, was to give further understanding of hemocyte function on the shell repair process in the Pacific oyster, Crassostrea gigas.

\section{MATERIALS AND METHODS}

\section{Experimental animal}

Oysters (80-100 $\mathrm{mm}$ in shell height) were collected from an oyster farm in Pukman Bay, Korea. Epibiota and fouling matter were immediately detached and the oysters were then acclimated in a flow-through tank for $24 \mathrm{~h}$ without feed. For the in vivo shell repair experiment, a $5 \mathrm{~mm}$ diameterhole was drilled in the right valve of 60 oysters using an electric hand drill. The oysters were allocated in 3 of $20 \mathrm{~L}$ polypropylene tank containing $15 \mathrm{~L}$ of filtered seawater $(0.2 \mu \mathrm{m})$ and fed mixed marine algae (Chaetoceros simplex, C. gracillis, Isochrisis galbana and Tetraselmis tetrathele) at the concentration of $10^{5}$ cells/ml four times a day. The experimental water exchanged twice a day. Samples of regenerated shell surface were taken every seven days for 21 days for histological observation.

\section{Histological observations}

Images of drilled shell surface were captured by CCD camera (JVC KY-F1030, Yokohama, Japan) under a stereoscopic microscope (Olympus SZX-12, Tokyo, Japan). Newly regenerated shell fragments were taken from the drilled zone by forcep. For the histological observation, the fragments were stained by Hemacolor ${ }^{\circledR}$ stain kit (Merk, Damstadt, Germany) following manufacturer's instructions. The stained samples were then observed under a light microscope (Olympus BX-51, Tokyo, Japan) and captured by
image-Pro software (v. 6.0, Media Cybernetics, Inc., Maryland, USA) equipped with CCD camera (JVC KY-F1030, Yokohama, Japan).

For SEM observations, the shell fractions were fixed overnight with $4 \%$ glutaraldehyde and postfixed with $2 \%$ osmium tetraoxidein cacodylate buffer for 1 hour. After ciritcal point dry, the specimens were coated with gold. Detailed SEM observation was performed on outer suface of shell using Jeol JSM-6380LV (Tokyo, Japan) and energy dispersive spectroscopy (EDS) microanalysis (INCA system, Oxford Instruments, Oxfordshire, UK).

\section{Hemocyte incubation for organic calcium crystallization} Oyster hemolymph was withdrawn from the pericardial cavity with 21-gauge needle into $1 \mathrm{~mL}$ syringe. The hemolymph was then added to sterile culture wells and the hemocytes were allowed to settle and form monolayers. After $20 \mathrm{~min}$, the monolayer was gently rinsed in $0.1 \mathrm{M}$ phosphate-buffered saline $(\mathrm{pH}$ 7.4). A pH adjusted (pH 7.6) medium of $0.2 \mu \mathrm{m}$ filter-sterilized extrapallial fluid and seawater was added to culture wells and then were incubated in a $\mathrm{CO}_{2} \quad(5 \%)$ incubator at $25{ }^{\circ} \mathrm{C}$. The monolayers were examined by SEM (Jeol JSM-6380LV, Yokohama, Japan) at two day intervals for calcium granule formation. The components of the hemocytic granules were further characterized by an EDS microanalysis system (INCA system, Oxford Instruments).

\section{Results}

In the shell regeneration experiment, the oyster showed different two-way responses. Fig. 1 shows the aspect of two types of regenerated shell: one was an urgent repair facilitated by pumping the extrapallial fluid (extrapallial fluid mediated repair, EMR) through the hole and the other was a mantle lobe mediated slow repair (MMR). In EMR response, the oyster showed active valve movement with ejecting EPF through the hole. After 12 hour from EMR response, the hole was covered by transparent elastic membrane (Fig. 1a). In MMR, however, the mantle lobe was extruded out of the hole (Fig. 1b) and 

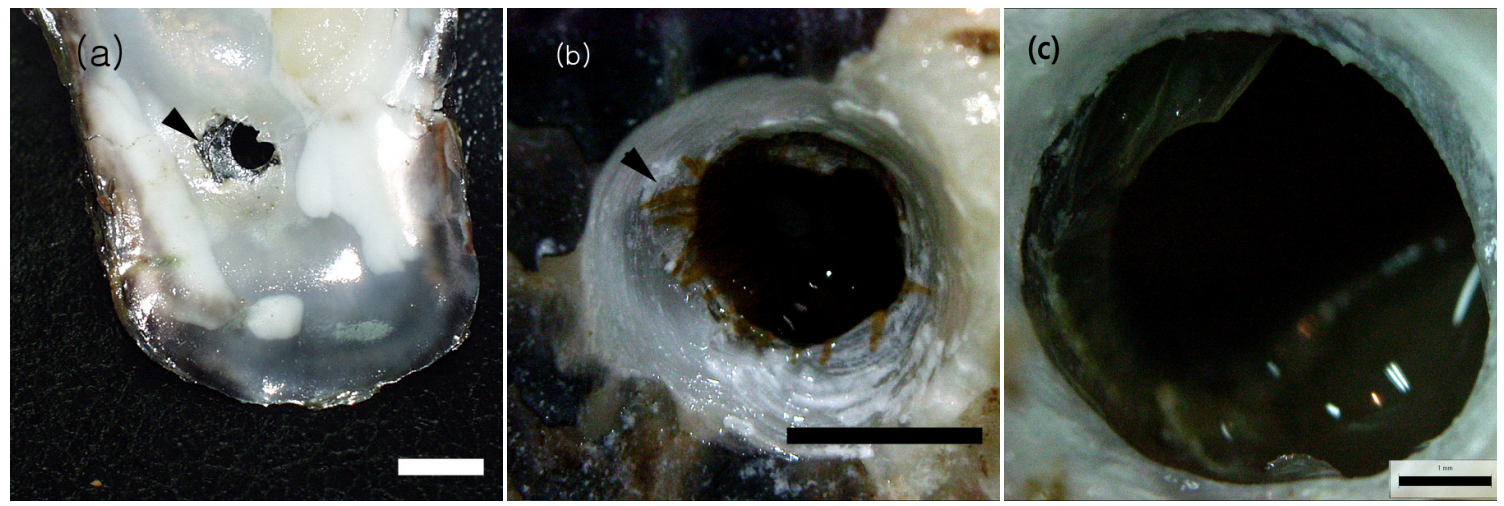

Fig. 1. Images of two types of shell repair events: extrapallial fluid mediated repair (EMR), a relatively rapid repair generated a transparent elastic membrane-like shell ( $\checkmark$ by pumping extrapallial fluid (a), and mantle lobe mediated repair (MMR), mantle lobes ( $\downarrow$ were extrude out through hole like anemone (b) and regenerated brownish chitin layer (c). Scale bar $=5 \mathrm{~mm}$ (a and b) and $1 \mathrm{~mm}(\mathrm{c})$.
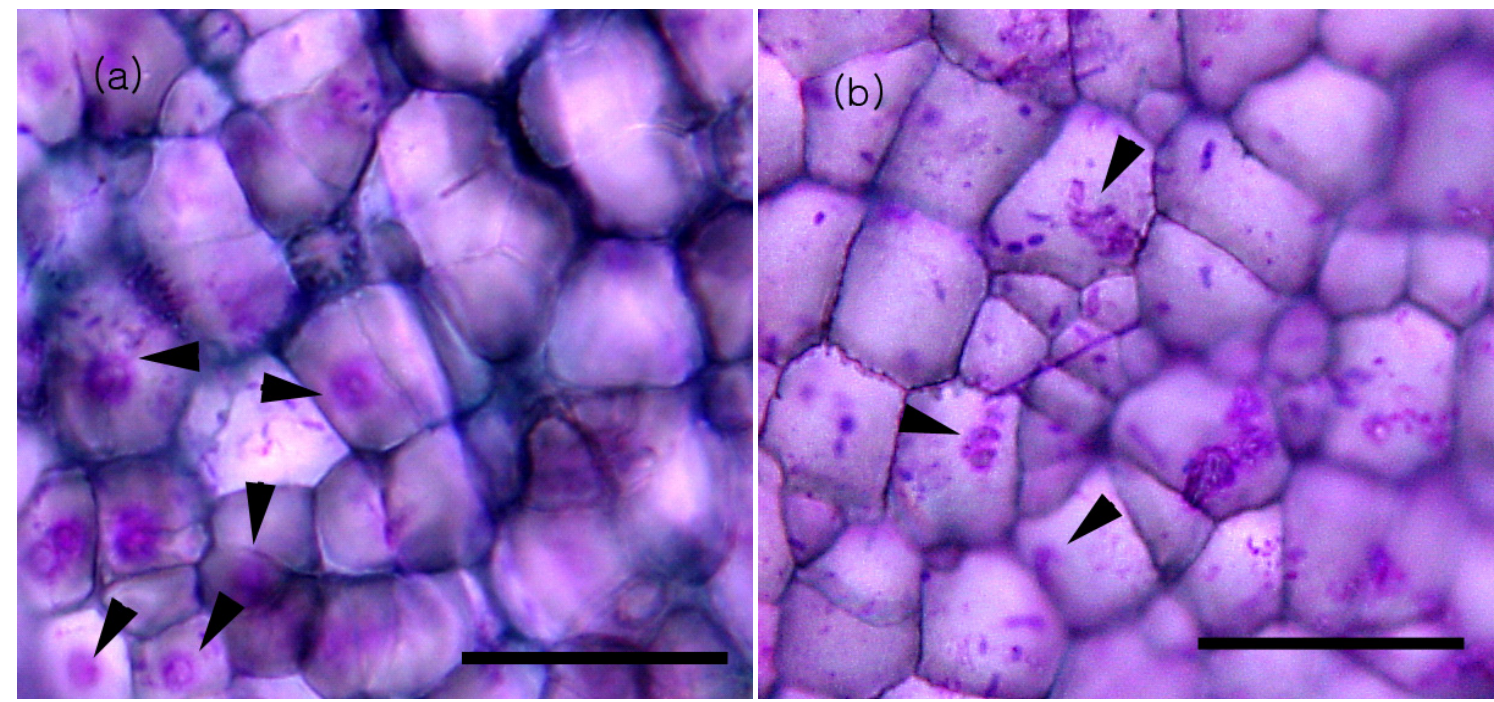

Fig. 2. Light microscopic images of regenerated shell layers from EMR at the $1^{\text {st }}$ day (a) and at $6^{\text {th }}$ day (b). The nuclei ( $\checkmark$ were clearly stained as red or pink by HemaColor ${ }^{\circledR}$ stain kit (Merk, Germany) and fragmented into pieces at $6^{\text {th }}$ day. Scale bar $=20 \mu \mathrm{m}$.

regeneration of shell was much slower than those of

EMR which produced a brownish and semi-transparent shell (Fig. 1c).

Histological observation of the regenerated shell from EMR suggested that the shell might be formed from aggregated hemocytes with clearly stained nuclei in their centres (Fig. 2a). The nuclei were, however, fragmented into small pieces at 6th day (Fig. 2b) and the membrane-like shell was hardened into transparent shell sheet.

In SEM observations, the shell from EMR showed a honeycomb-like structure forming a prismatic layer
(Fig 3a). At 6th day, globular shaped granules were observed from prismatic shell (Fig. 3), which was mainly composed of calcium (over 96\%, Fig. 4).

In order to identify the origin of the calcium granules, the hemocyte monolyer was incubated in $\mathrm{pH}$ adjusted $(\mathrm{pH}$ 7.6) medium of filter-sterilized extrapallial fluid and seawater. After 6 days incubation, globular shaped granules were observed by SEM observation. The elemental compostion of granules was identical with those of the regenerated shell's granules (Fig. 5). 


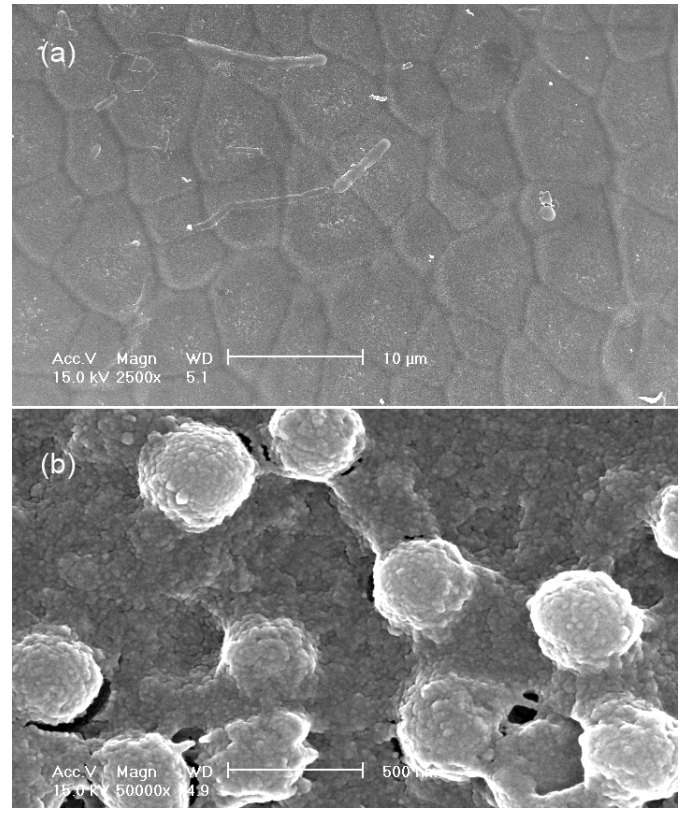

Fig. 3. SEM micrographs of prismatic shell at $1^{\text {st }}$ day (a) and at $6^{\text {th }}$ day (b). After calcification, the globular calcium granules were elevated from the prismatic shell. Scale bar $=10 \mu \mathrm{m}(\mathrm{a})$ and $500 \mathrm{~nm}(\mathrm{~b})$.

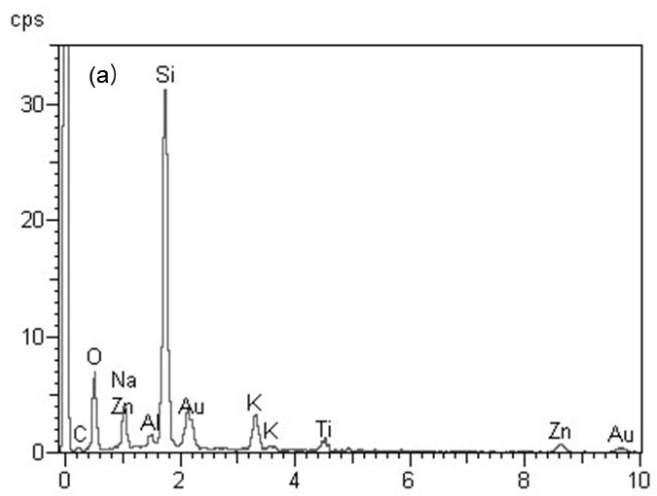

$$
\text { cps }
$$

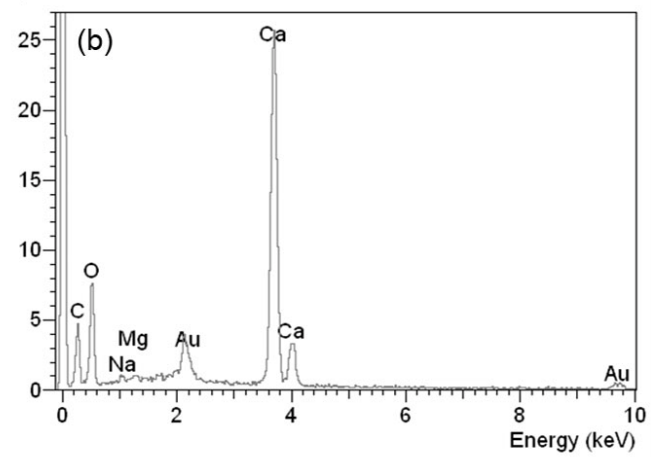

Fig. 4. EDS analysis of the regenerated layer at 1st day (a) and at 7th day (b). The elemental composition of the shell was dramatically changed to calcium (> $96 \%$ ) after calcification of prismatic shell.

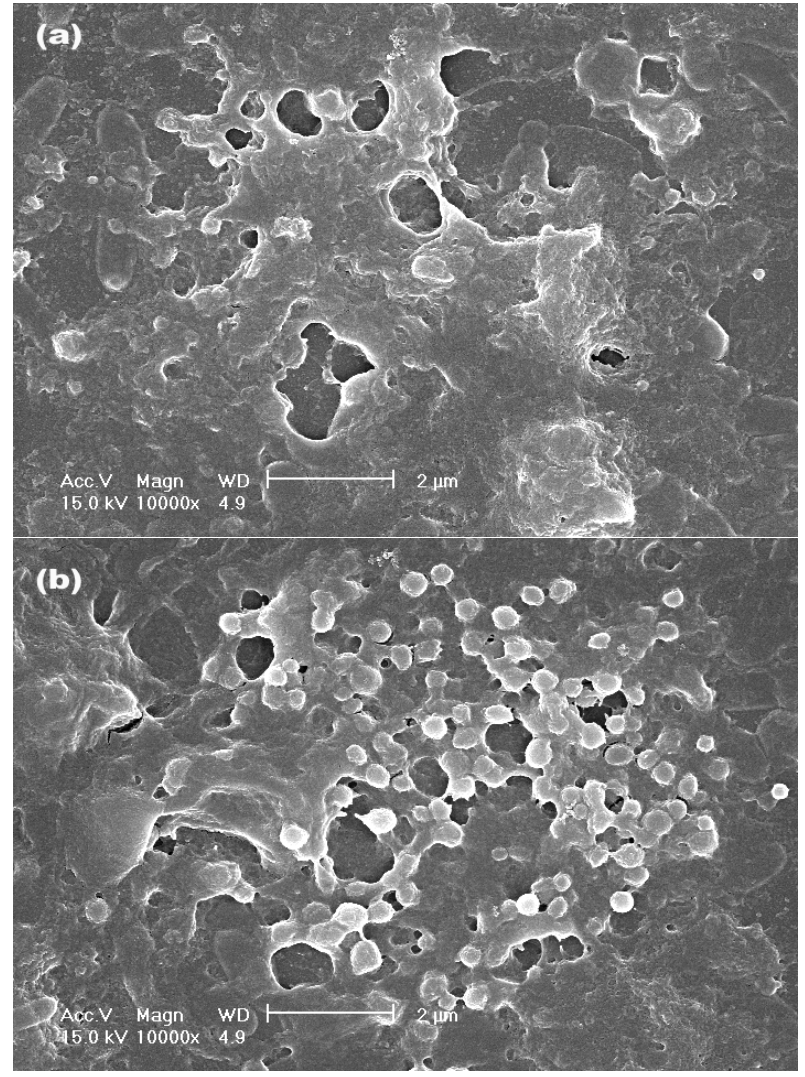

Fig. 5. SEM images of incubated hemocytic monolayer at $3^{\text {rd }}$ day (a) and at $6^{\text {th }}$ day (b). After 6 day incubation,globular calcium granules were formed from hemocytic monolayer which were morphologically and chemically identical with those from regenerated shell.

\section{DISCUSSION}

In the shell regeneration experiment, oysters respondedin two different ways: EMR and MMR. EMR usually formed a white semi-transparent membrane within $24 \mathrm{~h}$, whereas MMR took over 4 days to generate visible shell pieces. The shell piece was brownish and less transparent and harder than that produced by EMR. Although not being always observed, the pumping reaction was probably associated with the spawning season because the oysters were very mature and the shellsurface from EMR was highly contaminated with sperm and other protists (image not presented). The EMR response was not observed out of the spawning season. In most cases, MMR was common when oysters were exposed to shell repair conditions and the mantle lobe filled in the hole to form a physiological seal to isolate the 
extrapallial space from the seawater (Fleury et al., 2008).

The molluscan shell has so far been considered an organic matrix secreted from the mantle epithelium (Lowenstam and Weiner, 1989 Simkiss and Wilbur,1989; Wheeler,1992) or nascent intracellular crystals supplied by crystallogenic cells to the mineralization (Wilbur and Jodrey, 1952; Jodrey, 1953; Wilbur, 1964). However, Mount et al. (2004) recently suggested the direct involvement of granulocytic hemocytes in shell crystal production. In the present study, we also observed the direct involvement of hemocytes in the formation of prismatic layer and calcium crystallization. The regenerated layer showed a honeycomb-like structure with the aggregation of hemocytes with nuclei stained red. At $7^{\text {th }}$ day, the nuclei were fragmented and stained as particles but a honeycomb structure was still observed. This was consistent with the SEM observation in which globular calcium granule was extruded from the centre of the prisms because of biomineralization of intracellular cacium.

The prismatic shell had several globular granules measuring 100-500 $\mathrm{nm}$ in diameter. An obvious change ofthe elemental composition was observed from $\mathrm{Si}(>60 \%)$ to $\mathrm{Ca}(>90 \%)$ after calcification of the shell (Fig. 4). Recently, a shell-forming catalyst has been identified by several research groups (Miyashita et al., 2000; Thompson et al., 2000; Gotliv et al., 2005). However, the function and mechanism of the catalyst remain unclear.

The incubation of hemocytes in the present study, which represented granular calcium biomineralization, might provide the evidence for the origin of the prismatic layer. The hemocytes, incubated in a mixed medium of extrapallial fluid and seawater, formed several globular shaped calcium granules which were morphologically (size, $\geq 500 \mathrm{~nm}$ ) and chemically identical to those on the regenerated shell from EMR at the 6th day. Our findings suggested that the regenerated primsmatic shell might originate from an aggregation of hemocytes.

In conclusion, our study suggested that the prismatic layer of the oyster shell was mainly formed by hemocyte aggregation and that endogenous calcium component might support the calcification of regenerated shell during shell repair.

\section{ACKNOWKEDGMENTS}

This research was supported by a grant (CK3-101-1-0-1) from Carbon Dioxide Reduction \& Sequestration Research Center, one of the 21st Century Frontier Programs funded by the Ministry of Education Science and Technology of Korean government.

\section{REFERENCES}

Cho, S.M., Lee, Y.M. and Jeong, W.G. (2011). Effect of Polycylclic Aromatic Hydrocarbon (PAH) on Shell Repair in the Pacific Oyster, Crassostrea gigas. The Korean Journal of Malacology, 27:35-42.

Fleury, C., Marin, F., Marie, B., Luquet, G., Thomas, J., Josse, C., Serpentini, A. and Lebel, J.M. (2008) Shell repair process in the green ormer Haliotis turberculata: A histological and microstructural study. Tissue \& Cell, 40(3):207-218.

Gotliv, B.A., Kessler, N., Sumeral, J.L., Morse, D.E., Tuross, N., Addadi, L. and Weiner, S. (2005) Asprich: A novel aspartic acid-rich protein family from the prismatic shell matrix of the bivalve Atrina rigida. Chembiochem., 6(2):304-314.

Jodrey, L.H. (1953) Studies on shell formation III. Measurement of calcium deposition in shell and calcium turnover in mantle tissue using the mantle-shell preparation and $\mathrm{Ca}^{45}$. Biological Bulletin, 104:398-407.

Johnstone, M.B., Ellis, S. and Mount, A.S. (2008) Visualization of shell matrix proteins in hemocytes and tissue of the eastern oyster, Crassostrea virginica. Journal of Experimental Zoology, 310B:227-239.

Kadar, E., Lobo-da-Cunha, A. and Azevedo, C. (2009) Mantle-to-shell $\mathrm{CaCO}_{3}$ transfer during shell repair at different hydrostatic pressures in the deep-sea vent mussel Bathymodiolus azoricus (Bivalvia: Mytilidae). Marine Biology, 156:959-967.

Lowenstam, H.A. and Weiner, S. (1989) On biomineralization. Oxford University Press, Oxford, p. 336.

Marin, F., Luquet, G., Marie, B. and Medakovic, D. (2008)Molluscan shell proteins: Primary structure, origin and evolution. Current Topics in Developmenal Biology, 80:209-276.

Miyashita, T., Takagi, R., Okushima, M., Nakano, S., Miyamoto, H. and Nishikawa, E. (2000) Complementary DNA cloning and characterization of Pearlin, a new class of matrix protein in the 
nacreous layer of oyster pearls. Marine Biotechnology, 2:409-418.

Mount, A.S., Wheeler, A.P., Paradkar, R.P. and Snider, D. (2004) Hemcoyte-mediated shell mineralization in the eastern oyster. Science, 304:297-300.

Simkiss, K. and Wilbur, K.M. (1989)Bomineralization, cell biology and mineral deposition. Academic Press, San Diego, p. 337.

Thompson, J.B., Paloczi, G.T., Kindt, J.H., Michemfelder, M., Smith, B.L., Stucky, G., Morse, D.E. and Hansma, P.K. (2000) Direct observation of the transition from calcite to aragonite growth as induced by abalone shell proteins. Biophysical Journal, 79:3307-3312.

Wheeler, A.P. (1992) Mechanisms of Molluscan Shell Formation. In: Calcification in Biological systems. (ed by Bonucci), CRC Press, Boca Raton, pp.
179-216.

Wilbur, K.M. and Jodrey, L.H. (1952)Studies on shell formation. I. Measurement of the rate of shell formation using $\mathrm{Ca}^{45}$. Biological Bulletin, 103:269-276.

Wilbur, K.M. (1964) Shell formation and regeneration. In: Physiology of Mollusca Vol. 1. (ed by Willbur, K.M. and Yonge, C.M.), Academic Press. New York, pp. 243-282.

Wilbur, K.M. and Bernhardt, A.M. (1984) Effects of amino acids, magnesium and molluscan extrapallial fluid on crystallization of calcium carbonate: In vitro experiments. Biological Bulletin, 166:251-259.

Zhang, C. and Zhang, R. (2006) Matrix proteins in the outer shells of mollusk. Marine Biotechnology, 8:572-586. 